\title{
Changing pattern of poisoning in children in Newcastle, 1974-81
}

\author{
G R LAWSON, A W CRAFT, R H JACKSON
}

\begin{abstract}
All children aged under 15 years admitted to hospital in Newcastle upon Tyne between 1974 and 1981 with a diagnosis of poisoning were studied. After the introduction in 1976 of child resistant containers for salicylates and paracetamol, salicylate poisonings fell dramatically. The other most important medicines to cause poisoning in young children were tricyclic antidepressants, benzodiazapines, Lomotil (diphenoxylate and atropine), and iron preparations; these should also be packaged in child resistant containers by regulation. Few children had symptoms after poisoning with household products, but bleach, turpentine, and paraffin might also be packaged in child resistant containers. The numbers of adolescent girls admitted after deliberate self poisoning and of teenage boys admitted after ingestion of alcohol increased over the study period.
\end{abstract}

\section{Introduction}

Poisoning accounted for 32 deaths in children aged under 15 in $1976^{1}$ and an estimated 24000 admissions to hospital in 1977.2 Much effort has been put into trying to reduce this unnecessary toll of suffering, but this had little effect until the selective introduction of child resistant containers in January 1976. In March 1981, because of the apparent effectiveness of such containers for aspirin preparations, ${ }^{3}$ an agreement between the Pharmaceutical Society and the government resulted in the introduction of this safety packaging for all prescription medicines. There has been some opposition to this move, and its implementation by phar-

\footnotetext{
Children's Department, Royal Victoria Infirmary, Newcastle upon Tyne NE1 4LP

G R LAWSON, MB, MRCP, registrar

A W CRAFT, MD, MRCP, consultant paediatrician

R H JACKSON, MC, FRCP, consultant paediatrician

Correspondence to: Dr A Wraft.
}

macists is still far from universal. Many episodes of poisoning in childhood cause little more than a family scare as most medicines are fairly non-toxic even when taken in overdose, as are most household products and plants.

To define which substances are now important in childhood poisoning we reviewed all children admitted to hospital in Newcastle upon Tyne after poisoning between 1974 and 1981. Most accidental poisonings occur in children aged under 5, whereas poisoning in older children is often a deliberate, attention seeking gesture. We therefore reviewed the pattern of poisoning in three separate age groups.

\section{Methods}

We collected data on all children aged under 15 admitted with poisoning to the two major hospitals in Newcastle upon Tyne including teenage children admitted to adult wards. These hospitals are the only two in the city that admit poisoned children and serve a population for primary referral of 512600 . The age, sex, type of poison, and date were recorded for all children, and in addition a more intensive study was carried out for those children admitted in 1979. The notes of the children aged 9 and under who were admitted during this year were reviewed and the poisoning episode classified according to whether the children were asymptomatic; had mild to moderate symptoms including spontaneous vomiting, drowsiness, and hyperkinesis, etc; or had severe symptoms including ataxia, extreme irritability, myoclonic jerks, and convulsions.

The results were analysed for the three age groups 0-4 years, 5-9 years, and $10+$ years and according to the type of poison in three major categories-namely, medicinal products, household or non-medicinal products, and plants.

\section{Results}

During 1974-81 a total of 1720 children with poisoning were admitted to the two hospitals. Table I shows the numbers admitted each year in each age group.

0-4 years-Altogether 1111 children $(64.6 \%)$ were poisoned before their 5th birthday, of whom 649 were boys and 462 girls (ratio of 1.4: 1). Five hundred and sixty seven children were admitted during the five months of May to September (14.2 per month per year) and 544 during the remaining seven months ( 9.7 per month). Six hundred and 
seventy two children $(60 \cdot 5 \%)$ were poisoned with medicinal products, $399(35.9 \%)$ with household products, and $40(3.6 \%)$ with plants; table II shows the major substances in each category. The 672 children poisoned with medicinal products took 715 different medicines-that is, some children took more than one substance. Table III shows the yearly pattern of poisoning with the five major medicinal products. No major change occurred in the pattern of poisoning with household products or plants during the eight years.

TABLE I-Total number of children admitted for poisoning in Newcastle by age and year

\begin{tabular}{lrrrrrrrr}
\hline & 1974 & 1975 & 1976 & 1977 & 1978 & 1979 & 1980 & 1981 \\
\hline$<5$ years & 166 & 179 & 136 & 156 & 105 & 130 & 125 & 114 \\
$5-9$ years & 28 & 30 & 31 & 34 & 22 & 17 & 13 & 17 \\
$10+$ years & 33 & 48 & 39 & 54 & 57 & 58 & 59 & 69
\end{tabular}

TABLE II-Major substances taken in poisoning episodes in children aged under 5

\begin{tabular}{lrlr}
\hline Medicinal & & Non-medicinal & \\
Salicylates & 100 & Turpentine/paraffin & 106 \\
Tricyclic antidepressants & 80 & Bleach & 35 \\
Benzodiazapines & 80 & Rat poison & 30 \\
Iron & 61 & Disinfectant & 23 \\
Paracetamol & 41 & Alcohol & 17 \\
Barbiturates & 19 & Others & 188 \\
Lomotil & 14 & Plants & \\
Others & 321 & Laburnum & 23 \\
& & Others & 17 \\
\hline
\end{tabular}

TABLE III-Number of children aged under 5 admitted according to type of poisoning

\begin{tabular}{lrrrrrrrr}
\hline & 1974 & 1975 & 1976 & 1977 & 1978 & 1979 & 1980 & 1981 \\
\hline Salicylate & 24 & 34 & 11 & 10 & 3 & 10 & 3 & 5 \\
Paracetamol & 8 & 3 & 5 & 3 & 2 & 7 & 4 & 9 \\
Benzodiazepines & 7 & 11 & 7 & 12 & 7 & 11 & 14 & 11 \\
Iron & 10 & 10 & 9 & 4 & 6 & 13 & 6 & 3 \\
Tricyclic antidepressants & 11 & 9 & 10 & 11 & 12 & 10 & 9 & 8 \\
\hline
\end{tabular}

5-9 years-Altogether 192 children $\left(11 \cdot 2^{\circ}{ }_{0}\right)$ aged 5 to 9 were admitted with poisoning over the eight years ( 113 boys, 79 girls; male to female ratio $1 \cdot 4: 1)$. One hundred and twenty $\operatorname{six}\left(65 \cdot 6^{\circ}{ }_{0}\right)$ were admitted during May to September (3.2 per month per year) and the remaining $66\left(34.4^{\circ}{ }_{0}\right)$ during the rest of the year ( $1 \cdot 2$ per month). Seventy five $\left(39 \cdot 1^{\circ}{ }_{0}\right)$ took medicinal products, $49\left(25 \cdot 5^{\circ}\right)$ household products, and $68\left(35 \cdot 4^{\circ}{ }_{0}\right)$ plants (mostly laburnum seeds). The number of children admitted with laburnum seed poisoning was greatly reduced during the last three years of the study; there was no other consistent change in the pattern of poisoning in this group.

$10+$ years-Altogether 417 children $\left(24 \cdot 2^{\circ}{ }_{0}\right)$ aged 10 and over were admitted with poisoning (146 boys, 271 girls; male to female ratio $0 \cdot 5: 1$ ). Three hundred and eighteen ( 68 boys, 250 girls; male to female ratio $0.3: 1$ ) took medicinal products; 99 took household products (alcohol in 89 cases; 72 boys, 17 girls; male to female ratio $4 \cdot 2: 1$ ); and 10 were admitted after ingesting plants, usually laburnum seeds or toadstools. Table IV shows the yearly number of admissions for alcohol and other poisonings in this age group.

Children aged 9 and under admitted with poisoning in 1979 were studied in greater detail. Eighty six $\left(58 \cdot 5^{\circ}{ }^{\circ}\right)$ of the 147 such children had no symptoms at all, $44\left(29 \cdot 9^{\circ}{ }_{0}\right)$ had mild to moderate symptoms, and $17\left(11 \cdot 6^{\circ}{ }_{0}\right)$ had severe symptoms. Table $\mathrm{V}$ shows the major substances that caused symptomatic poisoning.

Solvent abuse-Ten children (seven boys, three girls) were admitted because of the effects of solvent abuse, one in 1978, one in 1980, and eight in 1981 .

TABLE IV-Number of children aged 10 and over admitted with poisoning by year

\begin{tabular}{lcccccccc}
\hline & 1974 & 1975 & 1976 & 1977 & 1978 & 1979 & 1980 & 1981 \\
\hline $\begin{array}{l}\text { Alcohol } \\
\text { All other agents }\end{array}$ & 30 & 8 & 5 & 11 & 11 & 20 & 9 & 21 \\
\hline Total & 30 & 34 & 43 & 46 & 38 & 50 & 48 \\
\hline
\end{tabular}

TABLE V-Presence of symptoms resulting from poisoning in 1979 in children aged 9 and under

\begin{tabular}{lrcc}
\hline & \multicolumn{3}{c}{ Symptoms } \\
\cline { 2 - 4 } & None & Mild to moderate & Severe \\
\hline Medicines: & & & \\
$\quad$ Benzodiazapines & 4 & 8 & 2 \\
Iron & 12 & 1 & 1 \\
Salicylates & 8 & 4 & 4 \\
Tricyclic antidepressants & 3 & 1 & $6 *$ \\
Paracetamol & 6 & 10 & \\
Other & 16 & & 2 \\
Household products: & & 2 & \\
$\quad$ Turpentine & 7 & 1 & \\
Bleach & 3 & 4 & \\
Alcohol & 20 & & \\
Other & & 3 & \\
Plants: & 6 & 4 & \\
$\quad$ Laburnum & 1 & & \\
Other & & & \\
\hline
\end{tabular}

*Lomotil (diphenoxylate and atropine), Kwells (hyoscine), Serenace (haloperidol; two cases), ephedrine, podophyllin.

Plastic hardener Napisan (potassium monopersulphate and sodium chloride).

\section{Discussion}

This survey shows that the problem of poisoning in children has by no means been solved. Admissions for poisoning remain a considerable burden on the paediatric services as well as an unnecessary trauma for children and their parents. More boys than girls were admitted at all ages below 10, after which more girls than boys were admitted, due to the number of teenage girls who took deliberate medicinal overdoses. The excess of poisonings in the summer months was only partly accounted for by plant poisonings and was somewhat surprising since most poisoning episodes occur indoors and children are much more likely to be outdoors during the summer.

In children under 5 the importance of poisoning by medicinal products is clear, though salicylate poisoning fell appreciably after the introduction of child resistant containers in 1976 (table I). The test protocol of the British Standards Institution is designed to prevent roughly $80 \%$ of children aged $2-4$ from opening such containers, and our figures appear to bear this out in practice, although we have no means of knowing whether the same amount of aspirin is being dispensed now as it was before 1976. Of the five children under 5 admitted with salicylate poisoning in 1981, one had taken junior aspirin that had not been in a child resistant container and had been in the house for many years, two had taken a compound preparation containing aspirin (Hypon) that was not, therefore, in a child resistant container, and one had taken Junior Disprin; only one had taken aspirin that was known to have been in a closed child resistant container. Poisoning with paracetamol did not show the same dramatic fall as poisoning with salicylates even though solid dose preparations of paracetamol are included in the salicylate regulations, which might be explained by the fact that preparations of paracetamol for children are in a liquid form not subject to these regulations. Table $\mathrm{V}$ shows the importance of benzodiazapines and tricyclic antidepressants as a cause of "symptom producing" poisoning. We remain convinced that more widespread use of child resistant containers is the correct way to reduce the number of children poisoned; if it is not practical for all medicines to be in such containers then a select list of dangerous compounds could easily be drawn up. We recommend as a result of this study that in addition to salicylates and paracetamol at least tricyclic antidepressants, benzodiazapines, Lomotil (diphenoxylate and atropine), and iron preparations should be dispensed in child resistant containers by regulation and not by voluntary agreement.

As previously reported by Goulding et $a l^{4}$ most poisonings with household products produced few symptoms. Possibly the more widespread use of child resistant tops, which is currently under consideration, would lead to a fall in the number of such poisonings, but again we would recommend careful selection of those substances that produce symptomatic poisoning. In this 
way consumer resistance to child resistant containers would be lessened. The general public is becoming accustomed to such containers and would probably accept their selective use for household products. From the present study it would appear that bleach, paraffin, and turpentine would be the most appropriate products for such packaging.

Plant poisonings are uncommon, and the falling number of children admitted with laburnum seed poisoning reflects an increasing awareness of the relative non-toxicity of these seeds ${ }^{5}$ and the fact that most children so poisoned are no longer admitted to hospital. Mild to moderate symptoms occur in a small proportion but generally do not warrant admission to hospital.

The figures for poisoning in children aged over 10 show two clearcut and important trends. The first is the steady increase in self poisoning among young adolescent girls, and the second the increase in admissions of teenage boys after ingestion of alcohol. Alcohol consumption is a growing and major problem among older children. A fairly recent death from poisoning in Newcastle was of a 12 year old boy who drank two bottles of sherry and inhaled vomit on his way to hospital. We presume that abuse of alcohol is part of the adolescent search for "kicks" and is similar to glue sniffing, which in this area has, until recently, been a cause of relatively few hospital admissions.

The main thrust of the prevention of poisoning in young children must be the extension of the use of child resistant containers. The history of the introduction of child resistant containers in the United States for both medicinal and nonmedicinal products by the Poison Prevention Packaging Acts was recently reviewed. ${ }^{6}$ From this there is clear evidence that such containers are effective, and in the United Kingdom this has already been shown for salicylates. ${ }^{3}$ Unfortunately, regulations rather than voluntary agreements appear to be necessary before most safety measures are effective, but the reduction in both suffering and occasional death must surely be worth a slight loss of freedom. There must of course be exceptions for the elderly and infirm, but the common occurrence of poisoning episodes in grandparents' homes should not be forgotten. Continued efforts to reverse the negative approach of some pharmacists must continue, and parental responsibility for the safety of their children should be emphasised and should include advice to parents to demand medicines in child resistant containers. Direct education of 5 to 9 year old children might also be beneficial.

The disturbing trends among older children towards both self destructive episodes and alcohol poisoning give cause for considerable concern. It represents one manifestation of the psychosocial problems that children are now experiencing. The increasing use and availability of alcohol by society as a whole must at least be partly responsible for this disturbing trend in adolescents.

\section{References}

${ }^{1}$ McLean W. Child poisoning in England and Wales: some statistics on admissions to hospital, 1964-1976. Health Trends 1980;12:9-12.

${ }^{2}$ Department of Health and Social Security. Hospital in-patient enquiry for 1977. London: HMSO, 1981.

${ }^{3}$ Sibert JR, Craft AW, Jackson RH. Child resistant packaging and accidental child poisoning. Lancet $1977 ; \mathrm{ii}: 289-90$.

${ }^{4}$ Goulding $\mathrm{R}$, Ashforth EK, Jenkins $\mathrm{H}$. Household products and poisoning. Br Med F 1978;i:286-7.

${ }^{5}$ Bramley A, Goulding R. Laburnum "poisoning." $\mathrm{Br}$ Med $\mathcal{F} 1981 ; 283$ : 1220-1.

6 Walton WW. An evaluation of the Poison Prevention Packaging Act. Pediatrics 1982;69:363-70.

(Accepted 7 April 1983)

\title{
Alcohol and the fetus in the west of Scotland
}

\author{
JOHN O BEATTIE， RUTH E DAY，FORRESTER COCKBURN， RAM A GARG
}

\section{Abstract}

Forty children with the fetal alcohol syndrome were identified in the west of Scotland. All were growth retarded and had abnormal facial features, and all those who were tested were found to have nuerological or developmental abnormalities. Two children died of associated physical defects. Most of the mothers were socially deprived, and all had drunk heavily while pregnant. Three women had subsequently died.

These findings provide clear evidence that in the west of Scotland maternal alcohol abuse during pregnancy is a significant cause of morbidity and mortality in children.

University Department of Child Health, Royal Hospital for Sick Children, Yorkhill, Glasgow G3 8SJ

JOHN O BEATTIE, MB, MRCP, registrar

RUTH E DAY, MB, MRCP, consultant paediatrician

FORRESTER COCKBURN, MD, FRCP, professor of child health

Department of Paediatrics, Southern General Hospital, Glasgow RAM A GARG, $M B$, paediatric registrar

Correspondence to: Professor Forrester Cockburn.

\section{Introduction}

In the past 10 years there has been increasing concern about the detrimental effects on the fetus of maternal alcohol abuse during pregnancy. During this period over 800 clinical and research papers relating to the teratogenic effects of alcohol have been published. ${ }^{1}$ The features shown by children affected by this fetal alcohol syndrome include growth failure before and after birth; central nervous system disorder (hypotonia, irritability and jitteriness, retardation, poor coordination, hyperkinesis); craniofacial abnormalities (microcephaly, short palpebral fissures, ptosis, strabismus, epicanthic folds, midfacial hypoplasia, hypoplastic philtrum, thin upper lip, and short upturned nose); and various associated physical abnormalities (of eyes, ears, mouth, cardiovascular system, genitourinary system, skeleton; haemangiomas; and hernias). ${ }^{2}$ Criteria for clinical diagnosis of the condition have been proposed. ${ }^{3}$

Although many questions about the pathogenesis remain unanswered, anxiety about the danger of even moderate drinking during pregnancy is now so great that in the United States the Surgeon General has advised mothers to abstain totally from drinking alcohol during pregnancy, ${ }^{4}$ a view recently echoed by the Royal College of Psychiatrists in Britain. ${ }^{5}$ Except for one recent study ${ }^{2}$ there has been little reported clinical experience of the fetal alcohol syndrome from Britain, and it has been suggested that the problem is insignificant in this country. ${ }^{6}$ This is surprising since alcohol abuse is certainly as common 